\title{
Review of: "7-Ketocholesterol: Effects on viral infections and hypothetical contribution in COVID-19"
}

Beyza Vurusaner

Potential competing interests: The author(s) declared that no potential competing interests exist.

This is an interesting, very urgent and updated review written by leading scientists in the field, which reports on the anti-viral effects of 7-ketocholesterol and associated pathologies including COVID-19. This manuscript mainly focuses on potential contribution of 7-ketocholesterol in the progression and outcome of COVID-19 and discusses about therapeutical strategies.

Only some minor points regarding the layout of the manuscript, which should be clarified:

a) Abstract, it is also advisable to insert an additional sentence focusing on the objective of the review.

b) In the first part, " origin and metabolism of 7-ketocholesterol", the first paragraph should be shortened since it has many chemistry information in a molecular biology journal.

c) In the first part, "origin and metabolism of 7-ketocholesterol", I suggest to insert new paragraphs regarding the descriptive parts on biological function of 7K and related signal transduction pathways.

Very minor points:

For consistency, "antiviral" should be replaced by "anti-viral" throughout the text. 